\title{
Pengaruh Kesesuaian Penempatan Kerja dan Kualifikasi Pendidikan Terhadap Kinerja Pegawai Rumah Sakit Bhayangkara Makassar
}

\section{The Influence of Suitable Employment and Educational Qualification towards the Performance of the Employees at Bhayangkara Hospital Makassar}

\author{
Hj. Afriyana Amelia $N^{1}$, Ricky Perdana Poetra ${ }^{2}$, Sri Paramitha Lestari Putri ${ }^{3}$ \\ ${ }^{123}$ STIKES Pelamonia Kesdam VII Wirabuana Makassar \\ Email: afriyana.enho@gmail.com, rickyperdana_poetra@yahoo.com.au, \\ lestaripelamonia@gmail.com \\ Jalan Garuda No.3AD Makassar Sulawesi Selatan
}

\begin{abstract}
ABSTRAK
Penempatan pegawai yang tepat merupakan salah satu kunci untuk mengoptimalkan kinerja pegawai itu sendiri. Penelitian ini bertujuan untuk mengetahui pengaruh kesesuaian penempatan kerja dan kualifikasi pendidikan terhadap kinerja pegawai di Rumah Sakit Bhayangkara Makassar. Jenis penelitian yang digunakan adalah kuantitatif dengan desain cross sectional study. Untuk variable independen dalam penelitian ini adalah penempatan kerja dan kualifikasi pendidikan sedangkan variable dependennya adalah kinerja pegawai. Dimana populasi dalam penelitian ini adalah pegawai rumah sakit Bhayangkara Makassar yaitu 611 orang dan yang memiliki ketidaksesuaian kualifikasi pendidikannya terhadap penempatan kerjanya yaitu sebanyak 115 responden. Teknik sampling yang digunakan adalah stratified random sampling dengan penarikan sampel menggunakan rumus slovin sehingga diperoleh sampel sebanyak 112 responden serta pengumpulan data menggunakan kuesioner. Analisis data yang digunakan dalam penelitian ini adalah univariat, bivariat, dan Multivariat dengan menggunakan uji regresi linear berganda. Hasil penelitian dalam penelitian ini adalah dari hasil pengujian hipotesis diperoleh bahwa ada pengaruh factor akademis $t_{\text {hitung }}>t_{\text {tabel }}(2.136>1.663)$, factor pengalaman $t_{\text {hitung }}>t_{\text {tabel }}(13.148>1.663)$, faktor status perkawinan $t_{\text {hitung }}>t_{\text {tabel }}$ (2.970 $>1.663)$, factor pendidik $t_{\text {hitung }}>t_{\text {tabel }}(3.019>1.663)$, factor lingkungan $t_{\text {hitung }}>t_{\text {tabel }}$ (2.812 > 1.663). Penelitian ini merupakan dasar pertimbangan untuk meningkatkan kinerja pegawai ditunjang dengan peningkatan akademisi dengan pemberian pelatihanpelatihan sesuai bidangnya sehingga dapat menunjang kinerjanya.
\end{abstract}

Kata Kunci :Penempatan Kerja, Kualifikasi Pendidikan, Kinerja Pegawai

\section{ABSTRACT}

A proper employment of the employees is one key in optimizing their performances. The purpose of this research is to realize the influence of suitable employment and educational qualification towards the performance of the employees at Bhayangkara Hospital Makassar. This research is a quantitative type of research with cross sectional study design. The independent variables in this research include aspects such as employment and educational qualification, while the dependent variable is the performance of the employee. The population of this research are all employees at Bhayangkara Hospital Makassar with the amount of 611 people and among them, there are 115 people whose educational qualification unfitting their employment. The sampling technique used is the stratified random sampling by withdrawing samples through the Slovin formula to obtain 112 respondents as the research samples. Meanwhile, the data collection is conducted through questionnaires. Data analysis techniques used in this research are univariate, bivariate, and multivariate by using multiple linear regression tests. From this research, it is known that based on the hypothesis testing results, there is an influence of academic factor $t_{\text {count }}>t_{\text {table }}(2,136>1,663)$, experiential factor $t_{\text {count }}>t_{\text {table }}$ 
$(13,148>1,663)$, marital status factor $t_{\text {count }}>t_{\text {table }}(2,970>1,663)$, educatorial factor $t_{\text {count }}>t_{\text {table }}(3,019>1,663>1,663)$, and environmental factor $t_{\text {count }}>t_{\text {table }}(2,812>1,663)$. It is expected that this research is considered as one basic consideration to improve the performance of the employees, supported with academic improvements by providing trainings based on their respective fields to boost their performances.

Keywords: employment; educational qualification; performance of the employee

\section{PENDAHULUAN}

Rumah Sakit sebagai salah satu fasilitas pelayanan kesehatan yang merupakan bagian dari sumber daya kesehatan yang sangat diperlukan dalam mendukung penyelenggaraan upaya kesehatan. Penyelenggaraan pelayanan kesehatan di rumah sakit memiliki karakteristik dan organisasi yang sangat kompleks. Berbagai jenis tenaga kesehatan dengan perangkat keilmuannya masing-masing berinteraksi satu dengan yang lainnya. Ilmu pengetahuan dan teknologi kedokteran yang berkembang sangat pesat yang harus diikuti oleh tenaga kesehatan dalam rangka pemberian pelayanan yang bermutu, membuat semakin kompleksnya permasalahan dalam rumah sakit. Pada hakekatnya rumah sakit berfungsi untuk tempat penyembuhan penyakit dan pemulihan kesehatan dan fungsi dimaksud memiliki makna tanggung jawab yang seharusnya merupakan tanggung jawab pemerintah dalam meningkatkan taraf kesejahteraan masyarakat Depkes RI (2009).

Penempatan kerja adalah suatu proses kegiatan yang dilakukan untuk menentukan seseorang pada posisi yang sesuai dengan formasi yang dibutuhkan. Ini berarti penempatan kerja pegawai dilakukan dalam rangka mengisi formasi yang disesuaikan dengan kemampuan, keterampilan dan keahlian pegawai yang bersangkutan (Yuliana \& Djumadi, 2015). Sehingga apabila seseorang ditempatkan selaras antara keterampilannya dan keahlian dengan bidang kerja maka pegawai tersebut akan lebih bergairah melaksanakan tugasnya yang berjuang pada meningkatnya kinerja pegawai yang bersangkutan (Wursanto, 2004).

Untuk mencapai tujuan organisasi secara efektif tentunya diperlukan sumber daya manusia (tenaga kerja) yang berkualitas dan sesuai dengan bidangnya. Saat ini, perusahaan dalam meningkatkan produktivitasnya melakukan suatu bentuk kegiatan yaitu penempatan tenaga kerja atau pegawai yang memiliki tingkat kompeten yang berbedabeda. Perbedaan kemampuan ini ditentukan berdasarkan hasil recruitment dan qualification perusahaan. Bahkan untuk promosi jabatan itu sendiri ditentukan berdasarkan penampatan kerja itu sendiri. Persaingan dalam dunia kerja yang semakin 
Hj. Afriyana Amelia N, Ricky PP, Sri Paramitha LP: The Influence of Suitable Employment and ...

meningkat memacu instansi untuk terus meningkatkan kinerja pegawai agar bisa bekerja dengan baik dan bisa bermanfaat baik untuk perusahaan maupun masyarakat (Siagian, 2004).

Penempatan merupakan salah satu aspek yang paling penting baik bagi karyawan maupun bagi perusahaan. Penempatan merupakan suatu proses yang sangat menentukan dalam mendapatkan karyawan yang kompeten yang dibutuhkan perusahaan, karena penempatan yang tepat dalam posisi jabatan yang tepat akan dapat membantu perusahaan dalam mencapai tujuan yang diharapkan (Qofiqi dan Nizar, 2016.). Hal tersebut sesuai dengan prinsip "The right man in the right place and the right man behind the right job" atau "penempatan orang-orang yang tepat pada tempat yang tepat dan penempatan orang yang tepat untuk jabatan yang tepat” (Hasibuan, 2016).

Berdasarkan penelitian yang dilakukan oleh Sopi dan Winda Tahun (2016) di Kantor BKD Kota Medan diperoleh hasil bahwa pendidikan dan penempatan secara bersama-sama berpengaruh positif dan signifikan terhadap variabel kinerja pegawai dengan f hitung 129.698 sedangkan ftabel pada= 0,05 dengan derajat pembilang 3 dan derajat penyebut 65 diperoleh ftabel 2,92 dari hasil diketahui fhitung $>$ ftabel, dan signifikansi 0,000 atau lebih kecil dari=0,05.

Penelitian yang di kemukakan oleh Evi Tahun (2017) di Kantor Kejaksaan Negeri Kendari menunjukkan hasil analisis deskriptif Penempatan Kerja (X) mempunyai ratarata skor jawaban responden sebesar 4,21 dan Kinerja Pegawai (Y) mempunyai rata rata skor jawaban responden sebesar 4,24 yang artinya antara penempatan kerja dan kinerja pegawai berada pada kategori baik. Hal ini menunjukkan bahwa penempatan kerja pada Kantor Kejaksaan Negeri Kendari Provinsi Sulawesi Tenggara yang dinilai berdasarkan persepsi responden telah dapat memberikan pengaruh terhadap kinerja pegawai. Hal tersebut dibuktikan dengan nilai signifikan $0,000<0,05$, sehingga hipotesis yang diajukan dapat diterima.

Penelitian yang di kemukakan oleh Dimas Tahun (2013) di Direktorat Jenderal Cipta Karya Kementrian Pekerjaan Umum Propinsi Riau menunjukkan bahwa nilai signifikansi adalah sebesar 0,000. Nilai signifikansi tersebut lebih kecil dibandingkan dengan nilai alpha sebesar 0,05. Sehingga dapat disimpulkan bahwa secara bersama-sama pendidikan dan penempatan kerja berpengaruh signifikan terhadap kinerja karyawan PT. Perkebunan Nusantara III Persero Medan. 
Rumah Sakit Bhayangkara Kota Makassar adalah rumah sakit rujukan di lingkungan POLRI dan masyarakat umum baik masyarakat kalangan atas maupun masyarakat kalangan bawah. Rumah Sakit Bhayangkara Makassar dinyatakan terakreditasi versi 2012 dengan status Lulus Madya pada tahun 2017, kemudian pada tahun 2018 Rumah Sakit Bhayangkara Makassar dinyatakan terakreditasi versi 2012 dengan status Lulus Paripurna, yang berlaku sampai tanggal 13 November 2020. Rumah Sakit Bhayangkara menempatkan pegawainya juga memerlukan penempatan kerja pegawai yang sesuai dengan bidangnya. Dari data yang saya dapatkan di rumah sakit bhayangkara kota makassar didapatkan data pegawai yang tidak sesuai dengan kualifikasi pendidikan terhadap penempatan kerjanya, sebanyak 155 orang yang terdiri dari : 1) Unit Manajemen Pelayanan : 77 orang, 2) Unit Manajemen : 78 orang.

\section{METODE}

Metode dalam penelitian ini adalah kuantitatif dengan pendekatan cross sectionalstudy dan observasi langsung yang dilaksanakan di Rumah Sakit Bhayangkara Makassar. Populasi dalam penelitian ini adalah pegawai yang tidak sesuai penempatan kerja dan kualifikasi pendidikannya sebanyak 155 pegawai. Metode pengambilan sampel dilakukan secara stratified random sampling dengan jumlah sampel 112 responden. Pengumpulan data yang dilakukan yaitu dari data primer dengan memakai kuesioner yang dibagikan kepada pegawai yang tidak sesuai penempatan kerja dan kualifikasi pendidikannya, data sekunder yaitu yang diperoleh dari pihak lain yang diperoleh dari dokumen Rumah Sakit Bhayangkara Makassar.Variabel dependen adalah kinerja pegawai dengan melihat hasil dari pembagian kuesioner kepada pegawai yang tidak sesuai penempatan kerja dan kualifikasi pendidikan. Sedangkan variabel independen adalah penempatan kerja (faktor akademis, faktor pengalaman dan faktor status perkawinan) dan kualifikasi pendidikan (faktor pendidik dan faktor lingkungan).Pengolahan data dilakukan dengan menguji hipotesanol (H0) serta tahap analisis data dimulai dari analisis analisis univariat, bivariat dan multivariate, uji $\mathrm{t}$ dan uji $\mathrm{f}$ yang digunakan untuk mengetahui variabel independen secara signifikan terhadap variabel dependen.Analisis data dilakukan secara elektronik dengan menggunakan computer program SPSS. Data yang telah diolah disajikan dalam bentuk narasi kemudian diberikan uraian untuk menjelaskan tujuan penelitian. 
Hj. Afriyana Amelia N, Ricky PP, Sri Paramitha LP: The Influence of Suitable Employment and ...

\section{HASIL}

Bagian berdasarkan hasil pengamatan dan pengukuran dilapangan, telah didapatkan beberapa hasil penelitian yang dilaksanakan di Rumah Sakit Bhayangkara Makassar diperoleh informasi yaitu sebagian besar responden merupakan pegawai dengan berumur dewasa awal 26-35 tahun terdapat 68 responden dengan persentase 60,7\% dan sebagian kecil merupakan pegawai dengan kategori umur remaja akhir berumur 17-25 tahun terdapat 20 responden dengan persentase 17,9 \%. Kategori jenis kelamin sebagian besar responden merupakan pegawai jenis kelamin perempuan terdapat 84 responden dengan persentase $75 \%$ sedangkan yang berjenis kelamin laki-laki terdapat 28 responden dengan persentase 25\%. Tingkat pendidikan responden yang tertinggi adalah tingkat pendidikan Diploma dengan jumlah 41 responden dengan persentase 36,6 \% dan yang terendah adalah tingkat pendidikan SMA/SMK Sederajat sebanyak 31 responden dengan persentase $27,7 \%$.

Tabel 1. Pengaruh Antara Faktor Akademis dengan Kinerja Pegawaidi Rumah Sakit Bhayangkara Makassar

\begin{tabular}{rrrrrrrrr}
\hline FaktorAkademis & \multicolumn{5}{c}{ Kinerjapegawai } & & Total & \multirow{2}{*}{$\mathrm{P}$} \\
\cline { 2 - 5 } & \multicolumn{3}{c}{ Baik } & \multicolumn{2}{c}{ TidakBaik } & & \\
\hline Cukup & 82 & & 0 & 0 & 82 & 100 & \\
Kurang & 8 & 26,7 & 22 & 73,3 & 30 & 100 & 0,000 \\
\hline Total & 90 & 80,4 & 22 & 19,6 & 112 & 100 & \\
\hline
\end{tabular}

Tabel 1 diatas menunjukkan bahwa responden yang merasakan faktor akademis yang cukup dan memiliki kinerja yang baik ada 82 responden (100\%) dibandingkan dengan responden yang merasakan faktor akademis yang kurang sebanyak 8 responden (26,7\%) dari jumlah keseluruhan responden yang memiliki kinerja yang baik, sedangkan tidak ada responden yang merasakan faktor akademis yang cukup dan memiliki kinerja yang tidak baik dibandingkan dengan respondenyang merasakan faktor akademis kurang sebanyak 22 responden (73,3\%) dari keseluruhan responden yang memiliki kinerja yang tidak baik.

Hasil uji statistik dengan menggunakan uji chi-square diperoleh nilai $\mathrm{P}=0,000$ karena nilai $\mathrm{P}<0,05$ maka Ho ditolak yang berarti ada pengaruh antara faktor akademis terhadap kinerja pegawai di Rumah Sakit Bhayangkara Makassar. 
Tabel 2. Pengaruh Antara FaktorPengalamandenganKinerjaPegawaidi RumahSakitBhayangkara Makassar

\begin{tabular}{|c|c|c|c|c|c|c|c|}
\hline \multirow[t]{3}{*}{ FaktorPengalaman } & \multicolumn{4}{|c|}{ KinerjaPegawai } & \multirow{2}{*}{\multicolumn{2}{|c|}{ Total }} & \multirow{2}{*}{$\mathrm{P}$} \\
\hline & & Baik & & Baik & & & \\
\hline & $\mathrm{n}$ & $\%$ & $\mathrm{n}$ & $\%$ & $\mathrm{~N}$ & $\%$ & \multirow{4}{*}{0,000} \\
\hline Cukup & 82 & & 0 & 0 & 82 & 100 & \\
\hline Kurang & 8 & 26,7 & 22 & 73,3 & 30 & 100 & \\
\hline Total & 90 & 80,4 & 22 & 19,6 & 112 & 100 & \\
\hline
\end{tabular}

Tabel 2 diatas menunjukkan menunjukkan bahwa responden yang merasakan faktor pengalaman yang cukup dan memiliki kinerja yang baik ada 82 responden (100\%) dibandingkan dengan responden yang merasakan faktor pengalaman yang kurang sebanyak 8 responden (26,7\%) dari jumlah keseluruhan responden yang memiliki kinerja yang baik, sedangkan tidak ada responden yang merasakan faktor pengalaman yang cukup dan memiliki kinerja yang tidak baik dibandingkan dengan responden yang merasakan faktor pengalaman kurang sebanyak 22 responden (73,3\%) dari keseluruhan responden yang memiliki kinerja yang tidak baik.

Hasil uji statistik dengan menggunakan uji chi-square diperoleh nilai $\mathrm{P}=0,000$ karena nilai $\mathrm{P}<0,05$ maka Ho ditolak yang berarti ada pengaruh antara faktor pengalaman terhadap kinerja pegawai di Rumah Sakit Bhayangkara Makassar.

Tabel 3. Pengaruh Antara Faktor Status Perkawinan dengan Kinerja Pegawaidi Rumah Sakit Bhayangkara Makassar

\begin{tabular}{|c|c|c|c|c|c|c|c|}
\hline \multirow{2}{*}{$\begin{array}{r}\text { Faktor Status } \\
\text { Perkawinan }\end{array}$} & \multicolumn{4}{|c|}{ Kinerjapegawai } & \multirow{2}{*}{\multicolumn{2}{|c|}{ Total }} & \multirow{2}{*}{$\mathrm{P}$} \\
\hline & \multicolumn{2}{|r|}{ Baik } & \multicolumn{2}{|c|}{ Tidakbaik } & & & \\
\hline & $n$ & $\%$ & $n$ & $\%$ & $\mathrm{~N}$ & $\%$ & \\
\hline Berpengaruh & 90 & & 0 & 0 & 90 & 100 & \\
\hline TidakBerpengaruh & 0 & 0 & 22 & 100 & 22 & 100 & 0,00 \\
\hline Total & 90 & 80,4 & 22 & 19,6 & 112 & 100 & \\
\hline
\end{tabular}

Tabel 3 diatas menunjukkan bahwa responden yang merasakan faktor status perkawinan yang berpengaruh dan memiliki kinerja yang baik ada 90 responden (100\%) dan tidak ada responden yang merasakan faktor status perkawinan yang tidak berpengaruh dari jumlah keseluruhan responden yang memiliki kinerja yang baik, sedangkan tidak ada responden yang merasakan faktor status perkawinan yang berpengaruh dan memiliki kinerja yang tidak baik dibandingkan dengan responden yang merasakan faktor status perkawinan yang tidak berpengaruh sebanyak 22 responden (100 \%) dari keseluruhan responden yang memiliki kinerja yang tidak baik.Hasil uji statistik dengan menggunakan uji chi-square diperoleh nilai $\mathrm{P}=0,000$ karena nilai $\mathrm{P}<0,05$ maka 
Hj. Afriyana Amelia N, Ricky PP, Sri Paramitha LP: The Influence of Suitable Employment and ...

Ho ditolak yang berarti ada pengaruh antara faktor status perkawinan terhadap kinerja pegawai di Rumah Sakit Bhayangkara Makassar.

Tabel 4. Pengaruh Antara Faktor Pendidik dengan Kinerja Pegawai di Rumah Sakit Bhayangkara Makassar

\begin{tabular}{rrrrrrrrr}
\hline Faktorpendidik & \multicolumn{4}{c}{ Kinerjapegawai } & & Total & \multirow{2}{*}{$\mathrm{P}$} \\
\cline { 2 - 6 } & & Baik & \multicolumn{2}{c}{ Tidakbaik } & & & \\
\hline Tinggi & 90 & & 0 & 0 & 90 & 100 & \\
Rendah & 0 & 0 & 22 & 100 & 22 & 100 & 0.000 \\
\hline Total & 90 & 80,4 & 22 & 19,6 & 112 & 100 & \\
\hline
\end{tabular}

Tabel 4 diatas menunjukkan bahwa responden yang memiliki faktor pendidik yang tinggi dengan kinerja yang baik ada 90 responden (100\%) dan tidak ada responden yang merasakan faktor status pendidik yang rendah dari jumlah keseluruhan responden yang memiliki kinerja yang baik, sedangkan tidak ada responden yang memiliki faktor pendidik yang tinggi dan memiliki kinerja yang tidak baik dibandingkan dengan responden yang memiliki faktor pendidik yang rendah sebanyak 22 responden (100 \%) dari keseluruhan responden yang memiliki kinerja yang tidak baik.

Hasil uji statistik dengan menggunakan uji chi-square diperoleh nilai $\mathrm{P}=0,000$ karena nilai $\mathrm{P}<0,05$ maka Ho ditolak yang berarti ada pengaruh antara faktor pendidik terhadap kinerja pegawai di Rumah Sakit Bhayangkara Makassar.

\section{Tabel 5. Pengaruh Antara Faktor Lingkungan dengan Kinerja Pegawai di Rumah Sakit Bhayangkara Makassar}

\begin{tabular}{rrrrrrrrr}
\hline Faktorlingkungan & \multicolumn{4}{c}{ Kinerjapegawai } & Total & \multirow{2}{*}{$\mathrm{P}$} \\
\cline { 2 - 6 } & \multicolumn{3}{c}{ Baik } & \multicolumn{3}{c}{ Tidakbaik } & & \\
\hline Cukup & 90 & & 0 & 0 & 90 & 100 & \\
Kurang & 0 & 0 & 22 & 100 & 22 & 100 & 0.000 \\
Total & 90 & 80,4 & 22 & 19,6 & 11 & 100 & \\
\hline
\end{tabular}

Tabel 5 diatas menunjukkan bahwa responden yang memiliki faktor lingkungan yang cukup dengan kinerja yang baik ada 90 responden (100\%) dan tidak ada responden yang memiliki faktor lingkungan yang kurang dari jumlah keseluruhan responden yang memiliki kinerja yang baik, sedangkan tidak ada responden yang memiliki faktor lingkungan yang cukup dan memiliki kinerja yang tidak baik dibandingkan dengan responden yang memiliki faktor lingkungan yang kurang sebanyak 22 responden (100 \%) dari keseluruhan responden yang memiliki kinerja yang tidak baik. 
Hasil uji statistik dengan menggunakan uji chi-square diperoleh nilai $\mathrm{P}=0,000$ karena nilai $\mathrm{P}<0,05$ maka Ho ditolak yang berarti ada pengaruh antara faktor lingkungan terhadap kinerja pegawai di Rumah Sakit Bhayangkara Makassar.

Tabel 6. Model Summery Regresi Berganda Penempatan Kerja dan Kualifikasi Pendidikan Terhadap Kinerja Pegawai

\begin{tabular}{cccrr}
\hline Model & R & R Square & $\begin{array}{r}\text { Adjusted R } \\
\text { Square }\end{array}$ & $\begin{array}{r}\text { Std. Error of } \\
\text { the Estimate }\end{array}$ \\
\hline 1 & $.977^{\mathrm{a}}$ & .954 & .952 & .474 \\
\hline
\end{tabular}

Tabel 6 diatas menunjukkan bahwa koefisien determinasi (adjusted $R$ square) sebesar 0,952 nilai ini dapat disimpulkan bahwa presentase pengaruh variabel bebas ( Faktor Akademis, Faktor Pengalaman, Faktor Status Perkawinan, Faktor Pendidik, Faktor Lingkungan) terhadap variabel terikat (Kinerja Pegawai) adalah 85,3\% sedangkan sisanya $14,7 \%$ dipengaruhi oleh variabel lain.

Tabel7. UjiAnova

\begin{tabular}{rccccc}
\hline Model & $\begin{array}{c}\text { Sum of } \\
\text { squares }\end{array}$ & Df & $\begin{array}{c}\text { Mean } \\
\text { Square }\end{array}$ & F & Sig. \\
\hline Regression & 496.920 & 5 & 99.384 & 442.749 & $.000^{\mathrm{b}}$ \\
\hline Residual & 23.794 & 106 & .224 & & \\
\hline Total & 520.714 & 111 & & \\
\hline Total & 520.714 & 111 & & & \\
\hline
\end{tabular}

Tabel 7 diatas menunjukkan bahwa nilai sig 0,000, nilai F hitung sebesar 442.749 dan nilai $\mathrm{F}$ tabel sebesar 4,38, maka nilai sig $<0,05$ dan nilai $\mathrm{F}_{\text {hitung }}>\mathrm{F}_{\text {tabel }}$ yang berarti terdapat pengaruh antara variabel Faktor akademis, Faktor Pengalaman, Faktor Status Perkawinan, Faktor Pendidik, Faktor Lingkungan secara simultan (bersama-sama) terhadap kinerja pegawai.

\section{Tabel 8. Koefisien Regresi Berganda}

\begin{tabular}{rrrlrr}
\hline \multicolumn{1}{l}{ Model } & $\begin{array}{l}\text { Unstandarized } \\
\text { Coefficients }\end{array}$ & \multicolumn{2}{l}{$\begin{array}{l}\text { Standardizd } \\
\text { Coefficients }\end{array}$} & T & Sig. \\
\cline { 2 - 4 } & B & Std. Error & Beta & & \\
\hline 1.(Constant) & -1.089 & .219 & & -4.974 & .000 \\
\hline Faktor Akademis & .151 & .071 & .079 & 2.136 & .035 \\
\hline
\end{tabular}


Hj. Afriyana Amelia N, Ricky PP, Sri Paramitha LP: The Influence of Suitable Employment and ...

\begin{tabular}{rccccc}
\hline $\begin{array}{r}\text { Faktor } \\
\text { Pengalaman }\end{array}$ & 1.465 & .111 & .702 & 13.148 & .000 \\
\hline $\begin{array}{r}\text { Faktor Status } \\
\text { Perkawinan }\end{array}$ & .347 & .117 & .091 & 2.970 & .004 \\
\hline Faktor Pendidik & .401 & .133 & .129 & 3.019 & .003 \\
\hline $\begin{array}{r}\text { Faktor } \\
\text { Lingkungan }\end{array}$ & .239 & .085 & .073 & 2.812 & .006 \\
\hline
\end{tabular}

Tabel8menunjukkanmaka persamaan regresi yang diperoleh dari hasil perhitungan adalah : Kinerja Pegawai $(Y)=1.089+(0.151) X^{1}+1.465 X^{2}+0.347 X^{3}+0.401 X^{4}+$ $0.239 \mathrm{X}^{5}$, Persamaan regresi tersebut dapat dijelaskan sebagai berikut :

Persamaan tersebut menunjukkan bahwa :

Konstanta sebesar 1.089, mengandung arti bahwa nilai konsisten variabel faktor akademis, faktor pengalaman, faktor status perkawinan, faktor pendidik, dan faktor lingkungan adalah sebesar 1.089.Merupakan nilai koefisien regresi X1 = 0.151 artinya, apabila terdapat peningkatan variabel faktor akademis sebesar satu satuan sementara variabel independen lainnya maka kinerja pegawai Rumah Sakit Bhayangkara Makassar akan mengalami peningkatan sebesar 0.151.Faktor Pengalaman merupakan nilai koefisien regresi X2 $=1.465$ artinya, apabila terdapat peningkatan variabel faktor pengalaman sebesar satu satuan sementara variabel independen lainnya tetap maka kinerja pegawai Rumah Sakit Bhayangkara Makassar akan mengalami peningkatan sebesar 1.465.Faktor Status Perkawinan merupakan nilai koefisien regresi X3 $=0.347$ artinya, apabila terdapat peningkatan variabel faktor status perkawinan sebesar satu satuan sementara variabel independen lainnya tetap maka kinerja pegawai Rumah Sakit Bhayangkara Makassar akan mengalami peningkatan sebesar 0.347.Faktor Pendidik merupakan nilai koefisien regresi X4 $=0.401$ artinya, apabila terdapat peningkatan variabel faktor pendidik sebesar satu satuan sementara variabel independen lainnya tetap maka kinerja pegawai Rumah Sakit Bhayangkara Makassar akan mengalami peningkatan sebesar 0.401.Faktor Lingkunganmerupakan nilai koefisien regresi X5 $=0.239$ artinya, apabila terdapat peningkatan variabel faktor lingkungan sebesar satu satuan sementara variabel independen lainnya tetap maka kinerja pegawai Rumah Sakit Bhayangkara Makassar akan mengalami peningkatan sebesar 0.239 . 


\section{PEMBAHASAN}

Faktor akademis yang telah dicapai oleh pegawai selama mengikuti jenjang pendidikan harus mendapat pertimbangan dalam menempatkan dimana pegawai yang bersangkutan harus melaksanakan tugas dan tanggung jawab serta wewenang dan tanggung jawab(Sastrohadiwiryo, 2002). Hasil uji statistik dengan menggunakan uji regresi linier berganda diperoleh hasil bahwa ada pengaruh antara Faktor akademis terhadap kinerja pegawai. Hal ini sejalan dengan penelitian yang menyimpulkan bahwa hasil Uji Empiris pengaruh antara faktor akademis terhadap kinerja pegawai, menunjukkan nilai t hitung 4,997 lebih besar dari t tabel 2,05183 dan p value (sig) sebesar 0,000 yang dibawah alpha 5\%. Artinya bahwa faktor akademis berpengaruh terhadap kinerja pegawai di PT. Pegadaian Syariah Simpang Patal Palembang(Septarina, 2017). Terdapatnya pengaruh antara faktor akademis dengan kinerja pegawai di Rumah Sakit Bhayangkara Makassar seperti prestasi yang telah di capai oleh pegawai di rumah sakit ini yang menunjang kinerja pegawai di bidangnya masing-masing, seperti yang telah peneliti dapatkan pada saat melakukan penelitian bahwa pegawai yang ada di Rumah Sakit Bhayangkara Makassar kebanyakan menunjang kinerja pegawai tersebut di karenakan dari akademis yang telah dilalui oleh pegawai tersebut.

Pengalaman para Pegawai sejenis yang telah dialami sebelumnya, perlu mendapat pertimbangan dalam rangka penempatan pegawai. Pengalaman bekerja banyak memberikan kecenderungan bahwa pegawai memiliki keahlian dan keterampilan kerja yang relatif tinggi. Sebaliknya rendah tingkat keahlian dan keterampilannya (Sastrohadiwiryo, 2002). Faktor pengalaman kerja yaitu proses pembentukan pengetahuan atau keterampilan tentang metode suatu pekerjaan karena keterlibatan pegawai tersebut dalam pelaksanaan tugas pekerjaan. Hasil uji statistik dengan menggunakan uji regresi linier berganda diperoleh hasil bahwa ada pengaruh antara Faktor pengalaman terhadap kinerja pegawai. Penelitian ini sejalan dengan penelitian yang menyimpulkan bahwa Faktor Pengalaman, t hitung = 3,293 dengan signifikan 0.000 $<$ 0,05 maka dapat disimpulkan bahwa Ho ditolak Ha diterima atau Faktor Pengalaman $\left(\mathrm{X}^{2}\right)$ berpengaruh signifikan terhadap Kinerja Pegawai (Karina Octavia dkk, 2017). Terdapatnya pengaruh antara faktor Pengalaman dengan kinerja pegawai di Rumah Sakit Bhayangkara Makassar seperti pengalaman yang telah dijalani oleh pegawai di rumah sakit lain yang dapat menunjang kinerja pegawai sehingga dapat menyelesaikan pekerjaan tepat waktu, dengan pengalaman yang dimiliki oleh pegawai sebelumnya maka akan menunjang pekerjaan pegawai dirumah sakit yang sekarang. 
Hj. Afriyana Amelia N, Ricky PP, Sri Paramitha LP: The Influence of Suitable Employment and ...

Untuk mengetahui status perkawinan pegawai adalah hal yang penting. Dengan mengetahui status perkawinannya dapat ditentukan, dimana seseorang akan ditempatkan. Misalnya pegawai yang belum menikah ditempatkan di cabang perusahaan di luar kota dan sebaliknya pegawai yang sudah menikah di tempatkan pada perusahaan di dalam kota dimana keluarganya bertempat tinggal(Sastrohadiwiryo, 2002). Hasil uji statistik dengan menggunakan uji regresi linier berganda diperoleh hasil bahwa ada pengaruh antara faktor status perkawinan terhadap kinerja pegawai. Penelitian ini sejalan dengan penelitian yang menyimpulkan bahwa menunjukkan status perkawinan berpengaruh terhadap kinerja pegawai dinilai baik, karena nilai rata-rata keseluruhan pernyataan adalah sebesar 3,83 berada pada interval 3,40- 4,19 (Balz, 2014). Terdapatnya pengaruh antara faktor status perkawinan dengan kinerja pegawai di Rumah Sakit Bhayangkara Makassar seperti pegawai yang telah berstatus menikah lebih lambat menyelesaikan pekerjaannya karena pasti lebih fokus ke keluarganya dibandingkan pegawai yang belum menikah akan lebih cepat menyelesaikan pekerjaannya karena lebih leluasa dalam mengerjakan tugasnya.

Faktor Pendidik yaitu seseorang yang memikul pertanggungjawaban untuk mendidik. Pengertian Pendidik Menurut (UU. NO. 12, 2012) Tentang Pendidikan Tinggi adalah usaha sadar dan terencana untuk mewujudkan suasana belajar dan proses pembelajaran agar peserta didik secara aktif mengembangkan potensi dirinya untuk memiliki kekuatan spiritual keagamaan, pengendalian diri, kepribadian, kecerdasan, akhlak mulia, serta keterampilan yang diperlukan dirinya, masyarakat, bangsa dan negara. Hasil uji statistik dengan menggunakan uji regresi linier berganda diperoleh hasil bahwa ada pengaruh antara Faktor pendidik terhadap kinerja pegawai (Hamali, 2016). Penelitian ini sejalan dengan penelitian yang menyimpulkan bahwa nilai signifikansi dari pendidikan (X1) adalah 0,004 nilai ini lebih kecil dari nilai alphanya yang sebesar 0,05. Dengan demikian dapat dinyatakan bahwa pendidikan memiliki pengaruh signifikan terhadap kinerja karyawan PT. Perkebunan Nusantara III (Persero) Medan (Sunaryo, 2016). Terdapatnya pengaruh antara faktor Pendidik dengan kinerja pegawai di Rumah Sakit Bhayangkara Makassar seperti pegawai yang berlatar belakang S1 ditempatkan di jabatan yang lebih tinggi dari pegawai yang berlatar belakang D3 dan SMA, sehingga hal ini mampu menunjang kinerja pegawai. Jadi, dirumah sakit ini faktor pendidik memilih pegawai yang berlatar belakang pendidikan yang lebih tinggi untuk ditempatkan karena agar bisa mendidik yang berlatar belakang rendah. 
Faktor Lingkungan adalah kehidupan sosial,psikologi, dan fisik dalam rumah sakit berpengaruh terhadap pegawai dalam melaksanakan tugasnya. Seperti : a) tempat tinggal, b) kebudayaan, c) kelompok hidup bersama seperti keluarganya, teman, dll. Hasil uji statistik dengan menggunakan uji regresi linier berganda diperoleh hasil bahwa ada pengaruh antara faktor lingkungan terhadap kinerja pegawai. Penelitian ini sejalan dengan penelitian yang menyimpulkan bahwa Berdasarkan hasil analisis data yang telah dilakukan menunjukan bahwa terdapat pengaruh yang positif dan signifikan antara lingkungan terhadap kinerja karyawan pada Dinas Pendidikan, Pemuda dan Olahraga Kabupaten Sleman(Ginanjar, 2013). Pernyataan ini dibuktikan dengan hasil perhitungan uji t yang menghasilkan thitung sebesar 8,304 sedangkan tabel dengan taraf signifikansi sebesar $5 \%$ yaitu 1,984 maka thitung $>t_{\text {tabel }}(8,304>1,984)$, perbandingan tersebut mengartikan bahwa Ho ditolak dan Ha diterima yaitu terdapat hubungan yang positif dan signifikan antara lingkungan kerja dengan kinerja karyawan pada Dinas Pendidikan, Pemuda dan Olahraga Kabupaten Sleman. Terdapatnya pengaruh antara faktor lingkungan dengan kinerja pegawai di Rumah Sakit Bhayangkara Makassar seperti pegawai yang di rekrut berada di lingkungan tidak jauh dari rumah sakit, dan tempat kerja yang nyaman sehingga dapat menunjang kinerja pegawai dalam menyelesaikan tugasnya tenang.

\section{SIMPULAN}

Hasil penelitian menunjukkan bahwa faktor akademis berpengaruh terhadap kinerja pegawai di Rumah Sakit Bhayangkara Kota Makassar. Faktor pengalaman berpengaruh terhadap kinerja pegawai di Rumah Sakit Bhayangkara Kota Makassar. Faktor status perkawinan berpengaruh terhadap kinerja pegawai di Rumah Sakit Bhayangkara Kota Makassar. Faktor pendidik berpengaruh terhadap kinerja pegawai di Rumah Sakit Bhayangkara Kota Makassar. Faktor lingkungan berpengaruh terhadap kinerja pegawai di Rumah Sakit Bhayangkara Kota Makassar.

\section{UCAPAN TERIMA KASIH}

Ucapan terima kasih disampaikan kepada semua pihak yang membantu terlaksananya penelitian ini terutama dari 1) Direktorat Jendral Penguatan Riset dan Pengembangan Kementerian Riset, Teknologi, dan Pendidikan Tinggi 2) Institusi STIKES Pelamonia Kesdam VII Wirabuana dan 3) pihak Rumah Sakit Bhayangkara Makassar. 
Hj. Afriyana Amelia N, Ricky PP, Sri Paramitha LP: The Influence of Suitable Employment and ...

\section{DAFTAR PUSTAKA}

Balz, G. M. (2014). Pengaruh Status Pernikahan Terhadap Motivasi Kerja Karyawan Di Yogya Center Bandung. Fakultas Bisnis Dan Manajemen Universitas Widyatama, 2(1), 2014. https://doi.org/10.1038/132817a0

Depkes RI, 2009 (2009) 'Undang-Undang Republik Indonesia Nomor 44 Tahun 2009 Tentang Rumah Sakit', Jakarta, (rumah sakit), p. 40

Anwar (2017) 'Model Kepemimpinan Ideal Pada Fak Tarbiyah dan Keguruan: Studi Kasus di IAIN Sultan Amai Gorontalo'.

Agustin Diyah Irawati (2017) Hubungan Penerapan Pelayanan prima (service excellent) terhadap kepuasan pasien rawat jalan di instalasi farmasi rumah sakit umum daerah dr.sayidiman magetan tahun 2017.

Isra Yuliana, Djumadi, D. P. 'Penempatan Pegawai Dalam Meningkatkan Kinerja Di Lingkungan Kerja Badan Pengelolaan Keuangan Dan Aset Daerah Kota Samarinda, 2015.

Fahmi Irham, Manajemen Sumber Daya Manusia Teori Dan Aplikasi, 2016.

Ginanjar, R. A. (2013). Pengaruh Lingkungan Kerja Terhadap Kinerja Karyawan Pada Dinas Pendidikan, Pemuda Dan Olahraga Kabupaten Sleman. ManajemenPendidikan, $\quad$ 53(9), 16891699.https://doi.org/10.1017/CBO9781107415324.004

Hamali, A. Y. (2016). Pemahaman Sumber Manajemen Manusia: Strategi mengelolal karyawan. CAPS Yogyakarta (Media Pressindo Group). https://www.researchgate.net/publication/321714929_PEMAHAMAN_MANAJEM EN_SUMBER_DAYA_MANUSIA_STRATEGI_MENGELOLA_KARYAWAN

Hasibuan, Malayu S.P, 2008. Manajemen Sumber Daya Manusia. Edisi Revisi, PT.Bumi Aksara Jakarta.

Hasibuan, Malayu S.P, 2013. Manajemen Sumber Daya Manusia. Edisi Revisi, PT.Bumi Aksara Jakarta.

Dimas Dwi Prasetyo, Pengaruh Penempatan, Pendidikan Dan Pelatihan Terhadap Kinerja Pegawai Satuan Kerja Penataan Bangunan Dan Lingkungan Direktorat Jenderal Cipta Karya

Kementerian Pekerjaan Umum Propinsi Riau', 2013.Karina Octavia, Adolfina, \&Lucky.O.H.Dotulong. (2017). Pengaruh Penempatan Kerja Dan Pengalaman Kerja Terhadap Kinerja Karyawan Pada Pt.Bank Sulutgo Kantor Cabang Utama Manado. Jurnal EMBA: Jurnal Riset Ekonomi, Manajemen, Bisnis Dan Akuntansi, 5(2), 110. https://doi.org/10.3 5794/emba.v5i2.16520

Rori,W.J.,dkk,'Pendidikan, Pelatihan Dan Penempatan KerjaPengaruhnya Terhadap Kinerja Pegawai Di Kantor Inspektorat Kota Manado’, Jurnal EMBA, 2(2), p. 12, 2014.

Pentana, S. and Ardiani, W, 'Dampak latar belakang pendidikan, pelatihan dan penempatan pegawai terhadap kinerja pegawai',Jurikom, 3, pp. 435-442, 20111.

Notoadmodjo, S, . 2012 'Metode Penelitian Kesehatan'. Jakarta: Rineka Cipta.

Sastrohadiwiryo, B. S. (2002). Manajemen Tenaga Kerja Indonesia: Pendekatan Administratif Dan Oprasional. Bumi Aksara, 2002. https://books.google.co.id /books/about/Manajemen_tenaga_kerja_Indonesia.html?id=jDGopwAACAAJ\&redi r_esc $=y$

Septarina, M. (2017). Pengaruh Tingkat Pendidikan Dan Lama Bekerja Terhadap Kinerja Karyawan Pada PT. Pegadaian Syariah Simpang Patal Palembang. Ekonomi Dan Bisnis, 1(3), 14. http://eprints.radenfatah.ac.id/982/1/MIFTA SEPTARINA 13190171.pdf 
Sunaryo. (2016). Pengaruh Pendidikan Dan Penempatan Kerja Terhadap Kinerja Karyawan Di PTPN III Medan. Jurnal Ilmiah Manajemen Dan Bisnis, 17(1), 1-13. http://jurnal.umsu.ac.id

UU. NO. 12. (2012). Undang - Undang Republik Indonesia No 12 Tahun 2012 Tentang Pendidikan Tinggi. UU No 12, 3(1), 57. https://jdih.kemenkeu.go.id/ fullText/2012/12TAHUN2012UU.HTM

Yuliana \& Djumadi, D. P. (2015). Penempatan Pegawai Dalam Meningkatkan Kinerja Di Lingkungan Kerja Badan Pengelolaan Keuangan Dan Aset Daerah Kota Samarinda. Jurnal Administrative Reform, 3(4), 428-440. http://ejournals.unmul.ac.id/index.php/JAR/article/view/582

Qofiqi, Mohammad Nizar Al. 2016. Pengaruh Kompensasi terhadap Kepuasan Kerja dan Intention to Leave. Skripsi. Malang: Universitas Brawijaya.

\begin{tabular}{|l|r|}
\hline Submission & 18 Agustus 2020 \\
\hline Review & 23 September 2020 \\
\hline Accepted & 10 Oktober 2020 \\
\hline Publish & 26 Oktober 2020 \\
\hline DOI & https://sinta.ristekbrin.go.id/journals/detail?id=3576 \\
\hline Sinta Level & 10.29241/jmk.v\%vi\%i.458 \\
\hline
\end{tabular}

